\title{
Raoul de Houdenc, Meraugis de Portlesguez. Roman arthurien du XIII siècle, publié d'après le manuscrit de la Bibliothèque du Vatican
}

\section{Maria Colombo Timelli}

\section{(2) OpenEdition \\ 1 Journals}

Édition électronique

URL : http://journals.openedition.org/studifrancesi/27161

DOI : 10.4000/studifrancesi.27161

ISSN : 2421-5856

Éditeur

Rosenberg \& Sellier

\section{Édition imprimée}

Date de publication : 31 décembre 2006

Pagination : $572-573$

ISSN : 0039-2944

\section{Référence électronique}

Maria Colombo Timelli, « Raoul de Houdenc, Meraugis de Portlesguez. Roman arthurien du XIIIe siècle, publié d'après le manuscrit de la Bibliothèque du Vatican ", Studi Francesi [En ligne], 150 (L | III) | 2006, mis en ligne le 30 novembre 2015, consulté le 08 novembre 2020. URL : http://journals.openedition.org/ studifrancesi/27161; DOI : https://doi.org/10.4000/studifrancesi.27161

Ce document a été généré automatiquement le 8 novembre 2020.

\section{cc) $(9)$}

Studi Francesi è distribuita con Licenza Creative Commons Attribuzione - Non commerciale - Non opere derivate 4.0 Internazionale. 


\title{
Raoul de Houdenc, Meraugis de Portlesguez. Roman arthurien du XIII ${ }^{\mathrm{e}}$ siècle, publié d'après le manuscrit de la Bibliothèque du Vatican
}

\author{
Maria Colombo Timelli
}

\section{RÉFÉRENCE}

RAOUL DE HOUDENC, Meraugis de Portlesguez. Roman arthurien du XIII siècle, publié d'après le manuscrit de la Bibliothèque du Vatican, Édition bilingue. Publication, traduction, présentation et notes par Michelle szKILNIK, Paris, Champion («Champion Classiques Moyen Age», 12), 2004, pp. 538.

1 Meraugis de Portlesguez est un roman de longueur moyenne (un peu plus de 5900 octosyllabes), composé entre la fin du XII et le premier tiers du XIII ${ }^{e}$ siècle, par un auteur qui se nomme dans l'explicit, mais qui demeure pour nous une figure 'évanescente', selon les mots de Michelle Szkilnik, responsable de cette nouvelle édition: cependant, Raoul de Houdenc, à qui l'on doit également le Roman des Eles, texte allégorico-didactique de 660 octosyllabes, devait être assez célèbre en son temps pour que Huon de Mery le nomme à côté de Chrétien de Troyes dans son Tournoiement Antechrist (rédigé vers 1235-1240). Ce qui est sûr, c'est que Meraugis doit être postérieur aux romans de Chrétien, à la Première Continuation du Conte du Graal (version longue), ainsi qu'au Lancelot en prose, œuvres avec lesquelles il entretient des rapports denses et nombreux. Ce roman a aussi connu une certaine postérité, comme le prouvent la réapparition de plusieurs personnages et la reprise de certains motifs dans des œuvres arthuriennes du XIII siècle.

2 La première partie (1000 vers environ) est organisée comme un jeu-parti, sans doute sous l'influence d'André le Chapelain, sur la question suivante: doit-on aimer une 
femme pour ses qualités intérieures (opinion du protagoniste) ou par sa beauté (avis de Gorvain, son adversaire en amour)? L'affaire paraît réglée par le tribunal des dames, qui se prononce assez rapidement, mais doit être ensuite démontrée par les aventures vécues par les deux protagonistes masculins. Dans son roman, Raoul se fait l'émule et le rénovateur des thématiques abordées par Chrétien de Troyes: il imite et cite des (membres de) vers, renvoie explicitement au Conte du Graal (v. 7), reprend des personnages et des épisodes (celui de l'épervier d'Erec et Enide, par exemple); néanmoins, ces reprises ne se font pas sans qu'il y ait prise de distance humoristique: on goûte particulièrement le moment où Meraugis, pris par une de ses aventures, 'oublie' la dame qu'il aime à la Cité sans Nom (vv. 3403 et ss.). Une telle réécriture ironique des motifs romanesques ne peut qu'amener le lecteur à s'interroger sur le statut du chevalier et sur l'idéologie qui sous-tend la littérature courtoise. D'autre part, le lecteur implicite est souvent présent dans Meraugis, dans les dialogues fictifs que Raoul instaure avec lui: questions et réponses, souvent très rapides, commentent les choix et actions des personnages ou éclairent le point de vue de l'auteur.

Dans l'introduction, Michelle Szkilnik aborde aussi bien les questions littéraires auxquelles j'ai déjà fait allusion, que philologiques et linguistiques. S'agissant d'une nouvelle édition, après celles fournies par Henri-Victor Michelant en 1869 et surtout par Mathias Friedwagner en 1897, elle présente la tradition manuscrite (trois manuscrits complets, mais celui de Turin est maintenant inutilisable, et deux fragments), justifie le choix du ms. de base (Bibliothèque du Vatican, Reg. lat. 1725), donne les principes d'édition. L'analyse de la versification (pp. 56-60) et l'étude de la langue (pp. 60-72) sont approfondies. La liste des 'expressions proverbiales et sentencieuses' donnée à la p. 72 peut néanmoins être enrichie: vv. 474-75 «A douce fontaine a beü / Qui si par tens est raempliz»(à rapprocher de Morawski, 99; Hassell, F110); v. 1354 «Savoir vaut miex que oïr dire» (proche de Morawski, 1283, 1284; Hassell, S43, S44); v. 3521 «Il quiert Paris en Engleterre»; vv. 3773-74 «Mes nus ne doit commencement / Löer dont la fins est mauvese» (commenté dans la note à ces vers, $p$. 311); v. 4909 «Que cil est fols qui fet folie» (Morawski, 492, 493, 1665; Hassell, F145; Di Stefano, s.v. fou); v. 5617 «J'a bone cage a metre oisiax» (à rapprocher de Morawski, 99; Hassell, F110); par ailleurs, il faudra corriger le prénom de Morawski, cité dans la note 107 comme 'Jean', en Joseph.

4 Rien n'est dit quant à la traduction en prose, très libre (ce qui explique la présence du glossaire): l'éditrice n'hésitant aucunement à avoir recours à des expressions de la langue familière et à des tournures très modernes, le lecteur non spécialiste sera d'autant plus ravi par l'intrigue, mais perdra en contrepartie beaucoup de la 'couleur médiévale' que d'autres traducteurs s'efforcent en revanche de conserver. Devant la qualité de la version en français moderne, on regrette d'autant plus les fautes d'orthographe qui s'y relèvent (cf., à la p. 293: 'je n'i passerai qu'une nuit'; 'jusqu'à ce que je vous ai trouvé'; 'Accèdant de bonne grâce') et une ponctuation parfois incomplète (les incises et les propositions relatives accessoires notamment sont rarement isolées).

Le texte est accompagné de notes en bas de page signalant les renvois à l'intertexte, quelques problèmes de versification (vers hypo- ou hypermétriques), des questions linguistiques dignes d'intérêt. Aux nombreuses reprises des romans de Chrétien, que Michelle Szkilnik indique ponctuellement, on pourrait encore ajouter le passage où Lidoine, accompagnant Meraugis, aperçoit avant lui Laquis et avertit son ami (vv. 
2539-40), souvenir sans doute d'Enide prévenant Erec des dangers qui le menacent; ou encore le retour du personnage dit 'le Lait Hardi', déjà paru dans le même roman de Chrétien (v. 1677 éd. Mario Roques).

6 Il faut encore signaler la qualité de l'apparat philologique complémentaire. Le prologue qui ne figure que dans le manuscrit $\mathrm{W}$ est édité et traduit en annexe (pp. 447-49); suivent la liste des leçons rejetées et des particularités de V (pp. 451-60) et les notes sur les corrections et leçons maintenues (pp. 461-504). L'index des noms propres (pp. 501-11; on remarquera la glose qui accompagne Paris, 'ville de France'! p. 510) et le glossaire (pp. 513-25) renvoient, sauf exception, à toutes les occurrences dans le texte. La Bibliographie, en trois sections (textes, ouvrages généraux, études) occupe les pp. 527-35. 